\title{
Enredando Famílias: Estado e Família no Povoamento do Solo Nacional
}

Jair de Souza Ramos Maine e Morgan legaram à antropologia um par analítico para classificar as formas

UFF políticas e estatais - aquele que opõe parentesco e territorialidade - que gozou de longa vida e que ainda hoje parece se desdobrar na oposição freqüentemente enunciada entre Estado e família como instituições que disputam o controle dos indivíduos, de recursos materiais e simbólicos escassos.

Na contramão da idéia de uma soma zero entre poderes de Estado e poderes de família, um autor clássico como Victor Nunes Leal já nos mostrava, em Coronelismo, Enxada e Voto (1978), o modo pelo qual o poder das famílias pode ser reforçado pelos poderes de Estado. Numa direção complementar a esta, a análise de Elisa Pereira Reis (1991) acerca da constituição de agências de Estado encarregadas da produção e exportação de café no início do século XX revela a expansão das agências estatais concomitantemente ao fortalecimento de interesses privados. Nesse sentido, a autora se contrapõe à suposição de que o predomínio das oligarquias rurais na direção do Estado implicou a redução do espaço reservado ao poder público.

$\mathrm{O}$ caso que irei analisar neste artigo revela um projeto de ação no qual poder estatal e poder doméstico parecem se reforçar mutuamente. Tomarei por objeto as ações e as representações desenvolvidas pelos agentes do Serviço do Povoamento do Solo Nacional, que passarei a chamar simplesmente de Povoamento, agência do Ministério de Agricultura Indústria e Comércio responsável, desde sua fundação em 1907 até o início da década de 1930, pela implementação das políticas federais de imigração e colonização. E como procurarei mostrar, temos aqui agentes de Estado empenhados em procedimentos de territorialização - a montagem de núcleos coloniais -, cujas técnicas conferem um lugar privilegiado às famílias de imigrantes 
Neste texto irei abordar um dos aspectos desta política de povoamento, mais especificamente as práticas dirigidas à constituição de cadeias de autoridade através da apropriação das estruturas de auto-organização dos imigrantes e colonos, isto é, suas estruturas familiares. Estas práticas punham as famílias de imigrantes e colonos no centro do empreendimento de atração de imigrantes e montagem de colônias. Esta análise será desenvolvida tendo como referência o argumento de que as políticas de imigração e colonização jogaram um papel no interior de processos mais amplos de formação de Estados Nacionais. Papel que envolve, entre outros aspectos, o uso de técnicas de poder que, ao conformarem um campo de ações dos agentes que eram objeto destas políticas, contribuíram à construção da autoridade pública do governo federal. Assim, tentarei mostrar como a família é tomada como objeto e instrumento da ação estatal, na busca pela construção de autoridade pública.

\section{FAMÍLIA E ESTADO}

Partindo da advertência de Malinowski de que a análise antropológica das estruturas familiares deveria levar em conta a estrutura social mais ampla que Ihes confere forma e sentido, Yanagisako (1979) critica a pouca importância acordada aos mecanismos externos à ordem do parentesco no entendimento de como as famílias se estruturam. Yanagisako nos dá como exemplo da importância de mecanismo externos o caso de comunidades camponesas na Índia e na China, nas quais a organização da família está intimamente ligada ao regime de direitos jurídicos à propriedade da terra, tradicionalmente ocupada comunitariamente por seus membros. Uma conseqüência dessa definição jurídica é que em tais sociedades os homens, como herdeiros da propriedade, são colocados no centro da família, enquanto as mulheres são classificadas como membros subordinados ou periféricos (Yanagisako 1979: 163).

Ao conceder importância, na estruturação da família, a elementos outros que o parentesco, esta perspectiva é particularmente útil à análise de um contexto no qual agentes de Estado tomaram explicitamente famílias, e não indivíduos, como alvo e instrumento de sua ação. Mais precisamente, permite chamar atenção para o fato de que as políticas de imigração subsidiada e de colonização no Brasil sempre fizeram da família do imigrante ou do colono uma unidade econômico-política de seus projetos de povoamento e de desenvolvimento.

A contextualização da família proposta por Malinowski e retomada por Yanagisako permite evidenciar também que a família é uma construção e não apenas uma atualização das regras de parentesco. Disso resulta a crítica da naturalização da família como uma unidade de análise auto-estruturada. Assim, ao invés de se tentar compreender a família do colono como uma mera variante da família camponesa, é necessário observar o modo 
como esta família é, ao menos parcialmente, produto e valor da política de povoamento.

Da Matta (1987) desenvolve de modo muito interessante esta dimensão da família como um valor na sociedade brasileira, e em especial no modo de funcionamento do Estado e da política brasileiras Porém, o objetivo aqui é ir um pouco mais além e, ao menos, chamar a atenção para o modo como, a partir do Estado, a família como valor se difunde na direção dos agentes sociais e contribui à organização dos imigrantes/colonos em famílias. Numa direção complementar a esta, Creed assinala os riscos da pesquisa centrada exclusivamente na família, destacando tanto o papel que a família como valor exerce no imaginário nacionalista quanto a sua contrapartida: que as opções disponíveis à existência e forma de famílias e unidades domésticas camponesas são modeladas como tais por meio não apenas de fatores econômicos, mas também pelas ações estatais e os valores por elas disseminados (Creed 2000:349).

Vejamos, a seguir, de que maneira as ações dos agentes do Povoamento eram dirigidas, ao mesmo tempo, à indução de comportamentos nos imigrantes/colonos e ao reconhecimento de sua própria autoridade.

\section{A CENTRALIDADE DAS FAMÍLIAS NA POLÍTICA DE POVOAMENTO}

Desde o início, a política de atração de imigrantes conduzida pelo governo federal definia a família como alvo e instrumento do Povoamento do Solo Nacional. Seguindo uma direção construída desde os governos imperiais (Seyferth 1974:54-5) e amplamente partilhada por agências estaduais, companhias de colonização e até mesmo por fazendeiros individualmente, o decreto de fundação do Povoamento definia a família do imigrante como o objeto de sua ação. É o que demonstra o capítulo sobre imigração do Decreto nº 6.455, de 19 de abril de 1907, através do qual eram aprovadas as bases regulamentares do Serviço do Povoamento do Solo Nacional, que dizia, em seu artigo 92:

“O Governo Federal promoverá a introdução de imigrantes que, sendo agricultores e acompanhados de família desejem fixar-se no país como proprietários territoriais, em lotes de núcleos coloniais ou de terras outras que satisfaçam as exigências deste decreto" (apud Bailly 1931).

De fato, as políticas de atração de imigrantes conduzidas tanto pelos estados quanto pela União tinham em comum o fato de tomarem a família do imigrante como alvo, por meio do financiamento das passagens ou da compra do lote ${ }^{1}$. Nestes termos, os diversos agentes estatais que conduziam a política imigratória no Brasil não apenas não se conformavam plenamente a uma realidade pré-existente como, ao contrário, se esforçavam por 
modelar a natureza e a forma do fluxo imigratório segundo seus próprios projetos, tendo sido razoavelmente bem sucedidos neste objetivo.

Exploremos um pouco mais este ponto. Se tomarmos como exemplo a imigração portuguesa para o Brasil, constatamos que, já no século XVIII, de uma população que alcançava tão somente dois milhões, cerca de 400 mil portugueses vieram para o Brasil. Outros mais continuaram a chegar de forma ininterrupta ao longo do século XIX e na maior parte do $\mathrm{XX}$, constituindo o maior contingente imigratório que o país recebeu ao longo de sua história. Em sua maioria, eles emigravam com recursos próprios e estavam envolvidos em redes familiares ou comunitárias que os auxiliavam tanto na partida de Portugal quanto na chegada ao Brasil. Estes imigrantes encaminharam-se preferencialmente para as cidades e, ao longo dos anos, parcela deles empreendeu inúmeras viagens de ida e volta entre os dois países, distanciando-se de um modelo rígido de fixação (Klein 2000).

Numa observação complementar a esta, Devoto observa que a imigração italiana para o Brasil tinha a especificidade de ser familiar, em contraste com o perfil individual dos imigrantes italianos que imigraram para os outros países americanos (Devoto 1999:217). Também Stolcke chama a atenção para o fato de que, diferentemente do que ocorreu nos demais países americanos, os fazendeiros paulistas insistiram, desde o primeiro momento, em contratar trabalhadores em unidades familiares (Stolcke 1982:40).

Estas observações revelam o contraste entre a direção desejada por agentes estatais e fazendeiros, de um lado, e o modo como se desenrolava a imigração de massa, de outro. Trata-se de algo bastante conhecido pelos estudiosos da imigração o fato de ela ser primordialmente um empreendimento masculino. Homens, que imigravam em grupos ou sozinhos, organizavam redes de solidariedade que resultavam em habitações coletivas, autênticas casas dos homens, onde se vivia de forma mais ou menos precária em razão do esforço por economizar dinheiro. Muitos desses homens eram casados e deixavam famílias no seu lugar de origem. Muitos voltavam de forma regular a seu lugar de origem (alguns meses por ano) e se deslocavam sucessivamente entre várias regiões de emigração, segundo a sazonalidade das ofertas de trabalho na lavoura dos produtos de exportação. Parcela desses homens estabeleciam relações amorosas na região de imigração e constituíam novas famílias sem abrir mão das de origem. Temos, assim, variedade de arranjos familiares, diversidade de unidades domésticas, enfim, separação entre trabalho, moradia e família. Ora, os agentes estatais brasileiros sonhavam construir um tipo-ideal de família camponesa onde parentesco e unidade doméstica estivessem em continuidade. Frente a este ideal se multiplicavam as reclamações dos agentes do Povoamento contra os imigrantes que se deslocavam para a Argentina, ou para as cidades, que não queriam ser camponeses, ou mesmo que não eram camponeses na sua origem.

O objetivo destas observações algo impressionistas sobre imigrantes que se movimentam segundo cálculos e suportes múltiplos é tornar mais visível o esforço, sobretudo estatal, de intervir neste processo complexo de 
forma a desenhar uma direção aos imigrantes através de uma série de mecanismos de atração e condução.

Assim, a família do imigrante/colono esteve no centro do empreendimento de atração de imigrantes e montagem de colônias não pela forma como os e/imigrantes se organizavam eles mesmos nos seus deslocamentos, mas pela iniciativa direta dos organizadores daquelas políticas.

Prova de que o privilégio acordado às famílias de imigrantes pelo Estado Brasileiro nada tinha que ver com a diversidade concreta destas é o fato de que o regulamento do Povoamento trazia, em seu artigo 96, uma definição administrativa de família imigrante, cujo cerne era sua concepção como unidade produtiva. Dizia o texto:

“A União restitui aos imigrantes espontâneos que forem agricultores, constituídos em famílias, com pelo menos com 3 pessoas maiores de 12 anos e menores de 50 , aptas para trabalho ${ }_{t}$ e que se estabelecerem como proprietários de terras, a importância correspondente às passagens de $3^{\text {a }}$ classe do porto de embarque ao de destino" (apud Bailly 1931).

Diga-se de passagem que o trabalho necessário à exploração da unidade doméstica é um dos fatores que definem o formato da família camponesa, e o que o Estado Brasileiro se esforçava por definir era exatamente a quantidade mínima de trabalho que constituiria a família do colono.

Mas o privilégio acordado às famílias tinha como contrapartida o que poderíamos chamar de uma 'desconfiança' frente ao imigrante individual, que se expressa bem no seguinte comentário do diretor do Povoamento, Joaquim Gonçalves Júnior:

“Em núcleo mantido pela União ou por ela auxiliado, o agricultor acompanhado de família poderá comprar a prazo ou à vista um lote rural; e o solteiro, ou que não tenha uma família em sua companhia, só poderá adquirir lote mediante pagamento à vista" (RSPOV 1910:3).

Analisemos com detalhe esta afirmação. O imigrante solteiro ou sem família podia comprar o lote colonial, mas não podia obter financiamento para fazê-lo. Em princípio isto se explica de forma quase óbvia pela quantidade de trabalho necessária à exploração do lote colonial. Contudo um pequeno contra-exemplo nos permite relativizar esta explicação: uma casa de homens solteiros, como tantas geradas como produto de migração e imigração, forneceria uma quantidade de trabalho superior ao de uma família que tem que contar com o trabalho infantil. De resto, estas casas de homens se encontram de forma incontável nas migrações nordestinas para a Amazônia durante a Batalha da Borracha, para as regiões de expansão da fronteira agrícola, e mesmo para os grandes centros urbanos como Rio de Janeiro e São Paulo. Estas casas de homens representam a possibilidade de uma extração máxima de trabalho combinada com um investimento mínimo nas condições de moradia. 
Mas a fragilidade de uma óbvia explicação econômica não reside apenas na comparação entre a rentabilidade do trabalho familiar versus rentabilidade do trabalho coletivo masculino. É preciso também que nos lembremos da conhecida observação marxista de que é apenas no interior de relações de produção plenamente capitalistas que o controle sobre o trabalho pode se dar de forma predominantemente econômica e não política. De modo que, fora das relações capitalistas de produção, não se pode pensar o controle sobre o trabalho senão sob termos, a um só tempo, políticos e econômicos. Ora, uma característica básica da organização do trabalho frente às casas de homens é a contraposição entre ênfase na violência como meio de controle da mobilidade e da produção do trabalhador - e penso aqui na definição de violência dada por Foucault: "uma relação de violência é dirigida aos corpos e às coisas, ela força, ela dobra, ela quebra, ela destrói, ela fecha todas as possibilidades" (Foucault 1984: 313), de um lado; e a extrema rotatividade e mobilidade dos trabalhadores. De modo que quanto maiores as condições de mobilidade que se abrem ao trabalhador, maior é a violência empregada no controle sobre seu corpo e sobre os resultados de seu trabalho.

Nestes termos, a família do imigrante era concebida como a garantia não apenas do financiamento oferecido pelo governo federal na forma de trabalho familiar, mas de sua adesão ao projeto de colonização. A família, ela mesma, era o patrimônio político e econômico do imigrante.

Podemos desenvolver esta questão afirmando que os imigrantes sem família configuravam indivíduos do ponto de vista do exercício de uma relação de poder que partia dos funcionários do Povoamento. Do ponto de vista econômico, a escolha do indivíduo como alvo da política de colonização seria inconsistente com a carga de auto-exploração econômica envolvida na produção nos lotes coloniais ${ }^{2}$, a menos que, como já vimos, houvesse alguma forma de associação coletiva entre homens. Isto porque a exploração do lote colonial era pensada como devendo ser conduzida sem auxílio de empregados. Se já no Império o uso de escravos fora quase sempre proibido nas colônias estatais (Diégues 1964:24), mais tarde, nas colônias fundadas no regime republicano, o isolamento que as marcava dificultava o acesso a outra mão-de-obra além daquela composta pelos próprios colonos, os quais só eram admitidos no empreendimento colonial no suposto de que ocupariam lotes próprios. Portanto, de fato, dificilmente um colono sozinho seria capaz de conduzir a exploração de um lote colonial que media em torno de 25 hectares. Isso tornava fundamental o papel da auto-exploração familiar, mesmo que sob o rótulo família se encontrassem agregados vindos da Europa para trabalhar no lote concedido ao chefe de família.

Mas a ênfase sobre o indivíduo era inconsistente, também, com o projeto político envolvido na colonização, uma vez que o universo social no qual eram montadas as colônias carecia dos recursos materiais e organizacionais que caracterizavam o exercício de poderes sobre indivíduos. Este ponto merece maior desenvolvimento. 
tomados como eixos de definição de valores, é fundamental como forma de conceber o universo social e nele agir. Por pessoa ele identifica uma "vertente coletiva da individualidade, uma máscara que é colocada em cima do indivíduo que desse modo se transforma em ser social". Na definição como pessoa, cada um é avaliado por referência a um segmento de coletividade a que pertence. Por contraste, o indivíduo é característico de sociedades onde os grupos que ocupam o lugar dos segmentos tradicionais são formados por associações de indivíduos, os quais são concebidos como livres e dotados de emoções e consciência próprias. Neste caso, não existe mediação entre o indivíduo e o todo (Da Matta 1978, capítulo 4).

O sistema de valores dominante na sociedade brasileira, segundo Da Matta, confere, por vezes, valor à definição como pessoa em detrimento da definição em termos do indivíduo. Isto não significa que o indivíduo deixe de existir, mas sim que a definição de alguém nestes termos implica a atribuição de características negativas. Dessa estrutura se deriva a prática, comum no Brasil, de expressar desprezo pelo indivíduo, tomando-o como alguém apartado da vida social, egoísta, incapaz de estabelecer laços etc.

As formulações presentes no decreto de fundação do Povoamento e no relatório de Joaquim Gonçalves Júnior, acima citado, confirmam a interpretação de Da Matta, na medida em que aqueles que eram concebidos como indivíduos, os solteiros e os sem família, eram objeto de uma desconfiança por parte dos agentes do Povoamento.

A meu ver, tal desconfiança está relacionada a tipos diferentes de exercício de poder segundo suas condições objetivas de aplicação sobre indivíduos ou pessoas. Em sua definição do poder disciplinar, Foucault afirma que este se caracteriza por separar, analisar e diferenciar os objetos de sua ação. Mais especificamente, "a disciplina 'fabrica' indivíduos; ela é a técnica específica de um poder que toma os indivíduos ao mesmo tempo como objetos e como instrumentos de seu exercício" (Foucault 1977:153). Em que pese Foucault jamais ter explicitado os aspectos morfológicos das sociedades nas quais as disciplinas eram exercidas, creio que este tipo de poder sobre indivíduos, que configura a disciplina, é indissociável da existência de estruturas sociais nas quais a complexidade crescente aproximou grupos sociais em cadeias de interdependência que emanciparam e civilizaram indivíduos ao mesmo tempo em que expandiam o poder estatal ${ }^{3}$.

Ora, a inexistência destas estruturas complexas tem como conseqüência a ineficácia do uso de mecanismos de poder que têm o indivíduo como alvo. Creio que este era o caso do exercício do poder de Estado sobre as populações coloniais. Afinal, muitos são os testemunhos da insuficiência de meios que garantissem a presença estatal constante nestas colônias ${ }^{4}$, e disso decorria a impossibilidade exercer a vigilância molecular que é característica do poder sobre indivíduos. Portanto, sobre indivíduos o Estado Brasileiro podia exercer mais a violência que expulsa ou prende do que a autoridade que dá ordens com alguma expectativa de legitimidade da parte de quem ordena 
e da parte de quem recebe a ordem. Decorre daí que para que os agentes do Estado Brasileiro pudessem aspirar a exercer autoridade sobre os imigrantes era necessário recorrer a estruturas dotadas elas mesmas, previamente, de autoridade junto dos imigrantes ${ }^{5}$. Era esta estrutura que conferia à família do imigrante papel central na estabilização da relação de dominação legítima dos funcionários sobre os colonos ${ }^{6}$.

\section{ATRAINDO FAMÍLIAS, REFORÇANDO FIGURAS DE AUTORIDADE}

Outra razão da centralidade das famílias na ação do Povoamento vinha da própria idéia de que o Povoamento configurava o objetivo último das políticas de imigração e colonização. Assim, o artigo 13 do capítulo 2 do decreto de fundação do Povoamento recomendava que as áreas coloniais tivessem...

“... área suficiente para a ampliação do núcleo, de maneira que os descendentes dos primeiros imigrantes localizados, membros de suas famílias, ou pessoas de suas relações, residentes no estrangeiro, possam, no caso de constituição de novas famílias, ou de ser por eles chamados, vir residir como proprietários de terras no mesmo núcleo ou nos arredores" (apud Bailly 1931).

A perspectiva aqui era de uma multiplicação não de indivíduos isolados mas de famílias. Os artigos 26 e 27 do mesmo decreto revelam isso. Como vimos, apenas a agricultores acompanhados de famílias se poderiam vender os lotes rurais a prazo. Na condição de indivíduo, o imigrante/colono só poderia adquirir o lote rural à vista. E mesmo esta possibilidade prevista na lei estava condicionada à existência de lotes disponíveis para venda. Isto porque o ritmo de montagem dos núcleos coloniais nem sempre acompanhava o volume de imigrantes atraídos pelos benefícios das passagens subsidiadas. Quando acontecia de chegarem à área colonial imigrantes em número maior do que os lotes prontos para serem ocupados, a preferência da ocupação era dada às famílias.

Assim, o inspetor do Povoamento em Santa Catarina, Jacinto Antonio de Mattos, informava em seu relatório ao diretor da agência, em 1909:

“Foram localizadas 399 famílias com 1845 pessoas e ficaram por localizar 20 famílias recém-chegadas, com 121 pessoas e 32 avulsos que não têm direito a lotes e se acham agregados às referidas famílias" (RSPOV 1909:175).

A única menção que se fazia à compra de um novo lote também era definida a partir da família. 0 artigo 28 dizia: “É permitido ao imigrante, acompanhado de família, adquirir novo lote desde que obtenha título definitivo do primeiro". Como vemos, o principal patrimônio com que o colono podia contar para se fazer digno do crédito 
estatal era sua própria família. Contudo, havia ainda uma condição fundamental para ter acesso a este crédito: a família deveria constar minimamente de "cinco pessoas aptas para o trabalho".

Observemos aqui que a definição de família para entrada no país e compra do primeiro lote exigia um mínimo de três pessoas aptas para o trabalho. Já para a compra do segundo lote este número aumentava, isto porque a expansão da propriedade era concebida como produto do crescimento familiar.

Outra expressão dessa ênfase no crescimento das famílias era o modo pelo qual se organizavam os censos, nos quais a contagem anual da população de colonos sempre era feita individualmente e em famílias, referindo os primeiros às segundas como no seguinte exemplo extraído do relatório do MAIC de 1913: “Estão estabelecidos nos núcleos federais, inclusive os emancipados, 5.820 famílias de agricultores com 29.316 pessoas"77 (RMAIC 1913).

Mas não era apenas o crescimento da família o alvo desejado na definição do decreto. Era, também, o crescimento numa determinada direção que se revela no artigo 29 do mesmo decreto, que dizia:

"Ao imigrante estrangeiro, que, sendo agricultor e contando menos de dois anos de entrada no País, contrair casamento com filho ou filha de brasileiro nato, ou ao agricultor nacional que se casar com estrangeira aportada a menos de dois anos como imigrante será concedido um lote de terras com título provisório" (apud Bailly 1931).

Aqui aparece a miscigenação como ideal último do crescimento das famílias. Devemos lembrar o predomínio, à época, da chamada teoria do branqueamento no que diz respeito à imigração (Seyferth 1996). Segundo esta teoria, que estava alicerçada nos pressupostos do racismo científico, o povo brasileiro era composto, em sua maior parte, da fusão de raças inferiores. Desta fusão resultaram tipos mestiços também inferiores. Seria, então, necessário que este processo de fusão continuasse e a ele fossem acrescentados indivíduos provenientes de raças superiores. Assim, através da importação de imigrantes brancos e europeus, seria possível a "regeneração" dos componentes étnicos que fundaram o Brasil e a produção efetiva de um "tipo" racial brasileiro mais eugênico porque possuidor de maior quantidade de sangue branco. Este ideal de branqueamento supunha, além da atração do imigrante europeu, sua mistura com os nacionais (Ramos 1996). E o casamento do imigrante com nacional seria a melhor expressão desta mistura.

Como nos ensina Marcel Mauss em La Nation há uma circularidade, na formação dos modernos estados nacionais, entre classificações sociais baseadas na idéia de raça e processos de constituição de identidades coletivas de tipo nacional. De fato, desde o século XIX e ao longo do século XX, a idéia de raça forneceu uma linguagem fundamental para a definição das identidades nacionais, sobretudo a partir da intervenção estatal. Ora, para os ideólogos brasileiros a nação brasileira era uma comunidade imaginada, concebida como fundada sobre a existência de uma unidade cultural e de uma unidade racial. Nesse sentido, o futuro tipo brasileiro de mestiço 
superior, advindo da mistura entre trabalhadores nacionais e imigrantes, teria como principal virtude fornecer um patamar mais elevado sobre o qual o povo brasileiro construiria sua unidade racial e cultural, servindo de fundamento à nação brasileira ${ }^{8}$.

Na medida em que a política do Povoamento colocava a família no centro de sua política de atração de imigrantes e de colonização e, ao mesmo tempo, indicava a mistura com os trabalhadores nacionais como uma direção desejável, ela fazia confluir dois eixos de definição da nação: o primeiro, como unidade racial; e o segundo, como uma grande família, uma família de famílias. Mas o que é significativo do que foi exposto até aqui é que, ao passo que o ideal de uma mistura racial ficou sempre por ser realizado na política de povoamento, a organização de núcleos coloniais com base em unidades familiares foi de fato implementada.

Resumindo o que dissemos até agora, verificamos que, se a política de subsídio às passagens internacionais tinha por objetivo trazer famílias, a de colonização, em decorrência, buscava alocar famílias em lotes coloniais, ao mesmo tempo em que se reservavam novos lotes na perspectiva de que famílias ligadas às famílias trazidas também viessem para o Brasil, e que todas estas famílias acabassem por se misturar com as famílias nativas. Como podemos ver, as relações familiares eram vistas como o meio de obter um crescimento populacional ordenado.

E do que deriva o adjetivo ordenado que aqui emprego? Ele diz respeito basicamente ao controle visado por esta política acerca de onde deveria se dar este crescimento populacional - no campo e mais especificamente nos núcleos coloniais -, quem seriam os agentes deste crescimento - os colonos de origem européia -, e como este crescimento deveria se dar - através da multiplicação em rede das famílias de colonos europeus, já adaptadas ao clima e às autoridades brasileiras, morando e produzindo em lotes coloniais na condição de pequenos proprietários e, futuramente, ligando-se pelo casamento com famílias brasileiras.

Para que este projeto de Povoamento ordenado através da família do imigrante/colono fosse levado a cabo era necessário o emprego de mecanismos que pudessem induzir os imigrantes a adotarem determinados comportamentos. Isto foi tentado através de algumas estratégias. A primeira delas, como analisei mais acima, foi a concessão de passagens internacionais a imigrantes agrupados em famílias.

Evidentemente esta prática deu margem a tentativas de burla com imigrantes que viajavam sozinhos se associando para gozar do benefício. Em geral esta prática era estimulada pelas próprias companhias de navegação, que aceitavam e mesmo reuniam emigrantes pobres em seus navios na expectativa de que suas passagens seriam reembolsadas pelos importadores de mão-de-obra. Assim, as companhias de navegação eram as primeiras interessadas em obter passageiros a todo o custo, posto que os contratos de correio impunham a regularidade das partidas mesmo que não houvesse passageiros a bordo. Para evitar a fraude, o governo federal tentava se certificar de que suas famílias de imigrantes eram autênticas, demandando das companhias de navegação listas 
contendo o nome, idade, estado, nacionalidade e profissão, grau de parentesco com o chefe de família e número de volumes de bagagem de cada imigrante.

Este expediente é digno de nota porque mostra o esforço estatal por fazer prevalecer sua concepção de família por sobre realidades diversas. Assim, além dos casos de fraude, a vigilância estatal recaía também sobre aquelas situações em que as concepções nativas dos emigrantes definiam como parte da família indivíduos que não se enquadravam na definição estatal brasileira de parentes consangüíneos e afins.

Mais importante, contudo, era o fato de que esta tentativa de controle se alicerçava sobre dois personagens os quais o Estado Brasileiro investia de autoridade. O primeiro era o capitão do navio que trazia imigrantes. $\mathrm{O}$ outro era o chefe da família imigrante?.

Ambos os personagens eram encarregados de mediar, ainda que parcialmente, a relação entre as autoridades brasileiras e os imigrantes. Ao capitão cabia a elaboração e a entrega das listas de imigrantes, bem como a responsabilidade pela fidedignidade das informações ali contidas. Uma vez desembarcados, os imigrantes tinham sua documentação checada pelas fiscais brasileiros que confirmavam ou não as informações recebidas do capitão. Caso elas não fossem confirmadas, os imigrantes eram deportados em navios da mesma empresa de navegação que os havia trazido.

Esta medida tinha por objetivo evitar fraudes cometidas pelas companhias de navegação ou mesmo pelos seus capitães, mas também de engajá-los no esforço de vigilância sobre os imigrantes. Podemos observar aqui o esforço por maximizar os precários mecanismos de controle à disposição do Estado Brasileiro através da estratégia de criar cadeias de responsabilidade.

A mesma estratégia foi utilizada em relação aos imigrantes definidos como chefes de família. Vários dos 'benefícios' oferecidos aos imigrantes/colonos eram concedidos através da mediação deste personagem.

Assim, no capítulo Il do decreto de fundação do Povoamento encontramos os artigos 40, 42 e 43, que diziam, respectivamente:

“Os preços dos lotes, com ou sem casa, quando comprados a prazo, bem como quaisquer auxílios quando não sejam remuneração de trabalho, ou classificados como gratuitos, constarão de caderneta entregue ao devedor, organizada em forma de conta corrente, e constituirão débito dos imigrantes, levado à conta do chefe de família, que deverá começar a amortizá-lo, em prestações anuais, o mais tardar no fim do segundo ano do seu estabelecimento.

(...)

Falecendo o chefe da família, em cujo nome houver sido expedido o título provisório ou definitivo de propriedade, o lote passará aos herdeiros ou legatários nas mesmas condições em que era possuído.

(...)

Se o lote tiver sido comprado a prazo e falecer o adquirente deixando pagas, pelo menos três prestações, serão dispensadas em favor da viúva ou dos órfãos as demais prestações ainda não vencidas, expedindo-se título definitivo de propriedade" (apud Bailly 1931) ${ }^{10}$. 
Produzidas alguns anos mais tarde, as "Instruções regulando o preço de venda e o processo de distribuição de lotes de terras em núcleos coloniais fundados por conta da União" traziam o mesmo destaque conferido ao chefe de família:

"Art. $7^{\circ}$ - O titulo provisório de lote rural será entregue ao chefe de família de agricultores, em seguida ao seu estabelecimento, se lhe faltarem recursos para o pagamento imediato, ou a quem nos termos dos arts. 28 ou 29 das bases regulamentares para o Serviço do Povoamento, aprovadas pelo couber, nos decreto n. 6.455 , de 19 de abril de $1907(\ldots)$

Art. $8^{\circ}$ - $O$ título definitivo de propriedade de lote rural será expedido em favor do agricultor que efetuar o pagamento à vista; do chefe de família que liquidar o seu débito, correspondente ao valor do lote (...)

Art. 10 - Nenhum colono poderá obter mais de um lote rural, salvo verificando-se o caso do art. 28 das bases regulamentares de 19 de abril de 1907, em que é permitido ao chefe de família adquirir até dois lotes" (apud Bailly 1931).

Temos aqui, em primeiro lugar, a constituição de um documento oficial: a caderneta de devedor, a qual é produzida pelo Estado Brasileiro e entregue a um imigrante específico, o chefe da família. Construída na forma de conta corrente, com a relação de débitos e créditos da família do colono, a caderneta devia trazer registrada desde a situação dos pagamentos pelo lote colonial até o consumo de instrumentos de trabalho junto à administração colonial. Devia informar também dos pagamentos recebidos pelo trabalho na montagem da colônia. A caderneta servia de documento da relação que se pretendia estabelecer entre colono e Estado Brasileiro, de modo a garantir a apropriação da terra nos termos da propriedade do lote colonial. Portanto, a caderneta dava materialidade a todo um conjunto de categorias abstratas: colono, Estado, dívida e propriedade ${ }^{11}$.

O que é relevante aqui é o fato de que esta relação era estabelecida entre Estado e família, e não entre Estado e cada indivíduo singularmente, ao mesmo tempo em que era mediada por um indivíduo em especial, o chefe de família ${ }^{12}$. Ele era o agente com a qual o Estado se relacionava e se comunicava. E esta mediação, definida não no interior da própria família mas a partir da relação com o Estado, tornava o chefe de família a unidade mínima de autoridade investida pelo Estado. A sua morte era a única que merecia destaque, porque com ela se quebrava a cadeia de autoridades que ligava o Estado Brasileiro a cada família. E quebrada a relação entrava em cena a repatriação dos familiares ${ }^{13}$. 


\section{CONCLUSÃO: CONSTRUINDO A CADEIA TUTELAR}

A articulação entre Estado e família, concebida em termos de mútua constituição, é um campo fecundo para determinados desenvolvimentos da antropologia política que, construídos em torno do conceito foucaultiano de poder, procuram identificar o modo como a política constrói seus objetos e sujeitos de poder e como isto se articula à constituição de novas identidades no mundo moderno (Shore e Wright 1997).

Nesta perspectiva, a política não apenas codifica normas sociais e valores, mas também contém modelos de sociedade que servem de guia para o comportamento e mapa para a ação. E o Estado é menos pensado em termos da imposição pura e simples de uma ordem pública, e mais em termos de um conjunto de dispositivos por meio dos quais se busca o reconhecimento nos agentes de Estado de sua capacidade de dirigir os demais indivíduos em direções específicas. Assim, o esforço por construir comportamentos entre aqueles que são objeto da ação implica ir além dos mecanismos de interdição de comportamentos ou de aceitação da ordem pública, implica produzir neles o reconhecimento da capacidade dos agentes de Estado em dirigi-los. E é na conjunção destes sentidos que estes agentes se esforçam por se tornarem autoridades frente aos demais agentes sociais. Isto remete diretamente ao conceito de poder de Foucault, entendido como:

“... un mode d'action qui n'agit pas directement et immédiatement sur les autres, mais qui agit sur leur action propre. Une action sur l'action, sur des actions éventuelles, ou actuelles, futures ou présentes. Une relation de violence agit sur un corps, sur des choses: elle force, elle plie, elle brise, elle détruit: elle referme toutes possibilités; elle n'a donc auprès d'elle d'autre pôle que celui de la passivité; et si elle rencontre une résistance elle n'a d'autre choix que d'entreprendre de la réduire. Une relation de pouvoir, en revanche, s'articule sur deux éléments qui lui sont indispensables pour être justement une relation de pouvoir: que 'l'autre' (celui sur lequel elle s'exerce) soit bien reconnu et maintenu jusqu'au bout comme sujet d'action; et que s'ouvre, devant la relation de pouvoir, tout un champ de réponses, réactions, effets, inventions possibles» (Foucault 1984: 313).

Nestes termos, podemos ler as técnicas utilizadas pelos agentes do Povoamento em direção às ações dos colonos/imigrantes, em especial no que diz respeito à sua auto-organização em famílias, como instrumentos por meio dos quais se buscava a adoção de determinados comportamentos e a difusão de determinados valores. Como tais, ações e representações de Estado estavam igualmente dirigidas à construção de autoridade, o que implicava o esforço por tornar os agentes e agências de Estado, suas ações e as representações por eles difundidas, elementos relevantes frente aos demais agentes sociais, de modo que estes últimos deviam levá-los em consideração em suas representações de si e em suas ações. 
Para concluir, quero assinalar que a idéia de uma cadeia de autoridades é fundamental para entendermos o nexo mútuo estabelecido entre Estado e família.

Já dissemos que os agentes do Povoamento visavam estimular os imigrantes/colonos a adotarem determinados comportamentos. Em outras palavras, visavam exercer uma relação de dominação e de interdependência, garantindo a probabilidade de que seus modelos de comportamento fossem adotados como uma referência legítima pelos imigrantes/colonos. Mas isto não era feito numa relação direta entre uma ou várias autoridades estatais e um conjunto de indivíduos, cada qual tomado em sua singularidade, tal como definido no célebre modelo do Panopticon descrito por Foucault, expressão mais acabada do modelo de poder exercido sobre indivíduos (Foucault 1977). Isto era feito através do estímulo à auto-organização dos colonos em famílias e, ao mesmo tempo, pela definição de um dos membros da família como o único interlocutor dos agentes de Estado. Logo, como responsável pelo comportamento de cada um dos membros da família. De fato, encontramos aqui algo que se assemelha mais ao que Foucault descreveu como mecanismos de governamentalidade, isto é, supunha-se a existência legítima de um governo do pai sobre mulher e filhos, ao mesmo tempo em que este poder era colocado em relação de continuidade com o governo estatal.

Assim, a forma de um indivíduo poder contar com os benefícios estatais era fazendo parte de uma família. Mas estar ligado a uma família não era o bastante, era necessário que a família tivesse um chefe, um cabeça. Desse modo, cada indivíduo se ligava a este centro, o chefe, que por sua vez se ligava aos funcionários na sede do núcleo colonial, que se situavam eles mesmos no interior da cadeia hierárquica do Povoamento, fechando um circuito que ligava construção de autoridades locais e centrais.

É de se esperar que, em muitos casos, houvesse uma coincidência entre a estrutura das famílias de colonos e este personagem. Que, de fato, a morte de uma mãe ou de uma criança não inviabilizasse a manutenção do vínculo colonial, ao passo que a morte de um pai fosse socialmente disruptiva, ou que coubesse ao pai o direito à punição de filhos e esposas. Mas isso em nada contradiz o esforço de dominação do Estado Brasileiro. Afinal, a estratégia executada pelo Povoamento não visava violentar a realidade, mas conformá-la, através da apropriação de estruturas pré-existentes. Nestes termos, a ação estatal reforçava as estruturas já existentes que constituíam as famílias dos subsidiados, ao mesmo tempo que constituía sua própria autoridade ${ }^{14}$. E onde não houvesse um cabeça, este deveria ser criado, pois esta era uma demanda exigida à família em sua relação com o Estado Brasileiro. Ele era o mediador do acesso aos benefícios oferecidos aos colonos. Disso resultava que o poder patriarcal ou era reconstituído seletivamente como expressão local da hierarquia Estatal, ou bem se impunha pela primeira vez ali onde não havia existido ${ }^{15}$. 
Em resumo, a construção dessa cadeia de autoridade se baseava na apropriação de práticas sociais constitutivas das próprias redes de interação social que eram objeto da política do Povoamento. Ao mesmo tempo, o recurso a estas práticas tinha por resultado a construção de laços de interdependência entre famílias de imigrantes e autoridades estatais. 


\section{NOTAS}

1 É interessante notar que o lugar da família nas políticas imigratória e de colonização, que se revela de forma evidente nas estatísticas oficiais, trouxe dificuldades aos analistas que se esforçavam por produzir análises quantitativas da demanda e da produtividade dos trabalhadores imigrantes a partir de agregados de indivíduos. Segundo Holloway: "Uma das dificuldades para calcular a necessidade do trabalho adotado no oeste paulista é que toda a família do colono contratava o seu trabalho como unidade. Portanto, em acréscimo ao trabalho dos genitores, a família incluía o trabalho das crianças como uma maior ou menor fração do trabalho adulto normal, dependendo da idade delas e do seu número" (apud Vangelista 1991:86).

2 Para uma interpretação das razões econômicas da prática de trazer os imigrantes em famílias para o trabalho nas fazendas de café, ver Stolcke (1982).

3 Para a análise da construção do indivíduo em termos de um processo de emancipação, ver Simmel, Freedom and individual in The heritage of Sociology (1971). Para uma análise dos processos mutuamente interdependentes de formação de estado e construção do indivíduo no interior de um processo mais geral de civilização, ver Elias (1993).

4 Um exemplo entre vários desta carência de meios é o fato de que, quando por ocasião da declaração de guerra à Alemanha, em 1918, foram fechadas as escolas alemãs nos núcleos coloniais onde não se ministrava o ensino de português nem o da história e geografia brasileiras, o governo federal não conseguiu substituí-las por novas escolas "genuinamente nacionais" (RSPOV 1918).

5 Um exemplo da distinção entre família e indivíduo do ponto de vista da administração é revelado em um trecho do relatório de 1909 do inspetor do Povoamento no Paraná em que este informava ter sido "expulso um holandês sem família, turbulento, a bem da ordem e tranqüilidade do núcleo" (RSPOV 1909: 186)

6 Numa situação homóloga, ainda que a morfologia social fosse diferente em cada caso, a sociedade do Antigo Regime francês enfrentava problemas similares no exercício de poder sobre indivíduos. E tal como nesta situação do exercício de poder estatal sobre as populações coloniais, a família configurava um objeto fundamental de estabilização da dominação. É o que nos mostra Donzelot: "Essa inscrição direta da família do Antigo Regime no campo político tem duas conseqüências no que diz respeito ao exercício do poder social. Em relação aos aparelhos centrais, o chefe de família responde por seus membros. Contra a proteção e o reconhecimento da situação de que se beneficia, ele deve garantir a fidelidade à ordem pública daqueles que dela fazem parte ... Daí decorre que a não pertinência a uma família, a ausência, portanto, de um responsável sócio-político coloca um problema de ordem pública. É ao nível das pessoas sem fé, sem eira, nem beira, mendigos e vagabundos que, por não estarem em nada ligados ao aparelho social, desempenham o papel de pertubadores nesse sistema das proteções e obrigações" (Donzelot 1980:50 - grifos do autor).

7 Opera aqui parcela dos mecanismos através dos quais a família é construída por meio de mecanismos que aparentemente a descrevem. Segundo Bourdieu: "La définition dominante, légitime, de la famille normale (...) repose sur une constellation des mots, maison, maisonnée, house, home, household, qui sous apparence de la décrire, construit en fait la réalité sociale. (...) Cela dit, s'il est vrai que la famille n'est qu'un mot, il est vrai aussi qu'il s'agit d'un mot d'ordre, ou mieux, d'une catégorie, principe collectif de construction de la réalité collective. (...) Dans tout usage de concepts classificatoires comme celui de famille, nous engageons à la fois une description et une prescription qui ne s'apparaît pas comme telle parce que elle est (a peu près) universellement acceptée» (Bourdieu 1994:13537).

8 Essa ênfase na produção de um povo esteve diretamente ligada à passagem da Monarquia à República, quando se tentou definir a existência de um povo brasileiro - cuja expressão seria o mestiço - como eixo simbólico da unidade nacional. Até então, este eixo era definido pela figura do imperador. Esse deslocamento encontra similar na história européia e foi assim descrito por Michel Foucault, para o caso da França, em entrevista ao periódico Quel Corps: "Numa sociedade como a do século XVII, o corpo do rei não era uma metáfora, mas uma realidade política: sua presença física era necessária ao funcionamento da monarquia. (...) [A república 'una e indivisível' - JSR] é uma fórmula imposta contra os girondinos, contra a idéia de federalismo à americana. Não há um corpo da República. Em compensação, é o corpo da sociedade que se torna, no decorrer do século XIX, o novo princípio. É esse corpo que será preciso proteger, de um modo quase médico: em lugar dos rituais através dos quais se restaurava a integridade do corpo do monarca, serão aplicadas receitas terapêuticas, como a eliminação dos doentes, o controle dos contagiosos, a exclusão dos delinqüentes. A eliminação pelo suplício é, assim, substituída pelos métodos de assepsia: a criminologia, a eugenia, a exclusão dos degenerados (...)" (Foucault 1986:145). 


\section{REFERÊNCIAS BIBLIOGRÁFICAS}

ABÉLÈS, Marc. 1990. Anthropologie de l'État. Paris: Armand Colin.

BAILLY, Gustavo Adolpho.1931. Legislação Agrícola Brasileira vol.n 5. Immigração-Colonisação. Rio de Janeiro: Imprensa Oficial.

BOURDIEU, Pierre. 1994. 'Esprit d'État: génèse et structure du champ bureaucratique'. In Les Raisons Pratiques: sur la théorie de l'action.Paris: Éditions du Seuil.

BRASIL, MAIC. 1909-1929. Relatórios anuais do MAIC.

BRASIL, MAIC. 1908-1912. Serviço de Povamento. Relatórios anuais.

CREED, Gerald W. 2000. "'Family Values' and Domestic Economies". Annual Review of Anthropology 29:329-355. California.

DA MATTA, Roberto. 1986 "A Família como Valor: considerações não-familiares sobre a família à brasileira". . 1978. Carnavais, Malandros e Heróis. Rio de Janeiro: Zahar

DIÉGUES Jr., Manuel. 1964. Imigração, Urbanização e Industrialização. Rio de Janeiro: Publicações do CBPE.

DONZELOT, Jacques. 1980. A Polícia das Famílias. Rio de Janeiro: Graal.

ELIAS, Norbert. 1993. O Processo civilizador. Vol. II: Formação do Estado e Civilização. Rio de Janeiro: Jorge Zahar Editor.

FOUCAULT, Michel. 1977. Vigiar e Punir. Petrópolis: Vozes.

. 1984. “Deux essais sur le sujet et le pouvoir" In: Dreyfus, Hubert e Rabinow, Paul. Michel Foucault. Un parcours philosophique. Paris: Gallimard.

. 1986. Microfísica do Poder. Rio de Janeiro: Graal.

LEAL, Victor Nunes. 1978. Coronelismo, Enxada e Voto. São Paulo: Alfa-Omega.

MAUSS, Marcel. 1970. “La Nacion” in Obras, Vol.III. Barcelona, Barrad.

OLIVEIRA Fo, João Pacheco.1988. O Nosso Governo: os Ticuna e o regime tutelar. São Paulo/Brasília: Marco Zero/CNPq.

PEIRANO, Mariza. 2002. "This Horrible Time of Papers": documentos e valores nacionais. Versão eletrônica. Brasília, Serie312empdf.pdf, 2002.

RAMOS, Jair de Souza. 1996. “Dos males que vêm com o sangue: as representações raciais e a categoria do imigrante indesejável nas concepções sobre imigração da década de 20". In Maio, Marcos Chor e Santos, Ricardo Ventura (orgs.) Raça, Ciência e Sociedade. Rio: Ed. Fiocruz.

REIS, Elisa P. 1991. “Poder privado e construção de Estado na Primeira República”. In R. Boschi (org.) Corporativismo e Desigualdade - A construção do espaço público no Brasil. Rio de Janeiro: Rio Fundo Editora/ luperj.

RENK, Arlene. 1997. A Luta da Erva. Um ofício ético no Oeste Catarinenese. Chapecó: Grifos. 
SEYFERTH, Giralda. 1974. A Colonização Alemã no Vale do Itajaí-Mirim: um estudo de desenvolvimento econômico. Porto Alegre: Movimento.

1996. "Construindo a Nação: hierarquias raciais e o papel do racismo na política de imigração e colonização." In Maio, Marcos Chor e Santos, Ricardo Ventura (orgs) Raça, Ciência e Sociedade. Rio de Janeiro: Ed. Fiocruz.

SHORE, Cris e WRIGHT, Susan. 1997. "Policy: a new field of Anthropology. In Anthropology of policy: Critical perspectives on governance and power . Londres: Ed. Routledge

SIMMEL, George. 1971. "Freedom and Individual”. In The Heritage of Sociology. Chicago: The University of Chicago Press.

STOLKE, Verena. 1982. "A Família que não é Sagrada" In Kolfes de Almeida, Maria Suely et alli. Colcha de Retalhos. São Paulo: Brasiliense

YANAGISAKO, Sylvia. 1979. "Family and Household: the analysis of domestic groups". Annual Review of Anthropology, 8:161-205. California. 


\section{Enredando famílias: Estado e família no Povoamento do Solo Nacional}

\section{RESUMO}

O caso analisado neste artigo revela um projeto de ação no qual poder estatal e poder doméstico parecem se reforçar mutuamente. Abordo aqui um dos aspectos da política de Povoamento do Solo Nacional, mais especificamente as práticas dirigidas à constituição de cadeias de autoridade através da apropriação das estruturas de auto-organização dos imigrantes e colonos, isto é, suas estruturas familiares. Estas práticas punham as famílias de imigrantes e colonos no centro do empreendimento de atração de imigrantes e montagem de colônias. A análise tem como referência o argumento de que as políticas de imigração e colonização jogaram um papel no interior de processos mais amplos de formação de Estados Nacionais. Papel que envolve, entre outros aspectos, o uso de técnicas de poder que, ao conformarem um campo de ações dos agentes que eram objeto destas políticas, contribuíram à construção da autoridade pública do governo federal. Assim, tento mostrar como a família é tomada como objeto e instrumento da ação estatal, na busca pela construção de autoridade pública.

PALAVRAS-CHAVE: Antropologia do Estado, família, imigração

\section{Entangling families: State and Family in the Population of National Land}

\section{ABSTRACT}

The particular case analyzed in this article reveals a project of action in which state and domestic powers seem to mutually reinforce each other. It is considered here one aspect of the "Populating National Land" policy, more specifically the practices aiming to the constitution of authority chains through the appropriation of auto-organizing structures of immigrants and colonizers, namely, family structures. These practices placed immigrant and colonizers' families at the center of the enterprise of immigrant attraction and the building up of colonies. This analysis has as its reference the contention that immigration and e colonization policies have played a role at the interior of more ample processes of National State formation. This role involves, among other aspects, the use of power techniques that, by making up a field of actions of those who were the object of these policies, have contributed to the construction of the public authority of the federal government. It is therefore shown how the family is taken both as an object and an instrument of state action, in the search for the construction of public authority. KEY WORDS: Anthropology of State, family, immigration 